\title{
FACULTY LIVED EXPERIENCES IN THE ONLINE ENVIRONMENT
}

\author{
SIMONE C. O. CONCEIÇÃO
}

University of Wisconsin-Milwaukee

\begin{abstract}
This phenomenological study investigated the meaning of the online teaching experience of college faculty when there was an absence of physical presence. Findings show that the online experience brings new dimensions to the teaching practice when there is an absence of physical presence: (a) The length and depth of engagement during the delivery of the course differs from face-to-face teaching and $(b)$ the experience is rewarding in new ways. Practical implications are suggested for adult education related to teaching improvement and instructional design.
\end{abstract}

Keywords: online teaching; distance education; faculty lived experiences

During the past few years, there have been very rapid changes in the field of adult and higher education associated with widening access and developments in communication and information technologies. A paramount initiative has been the extensive use of computer-mediated communication by higher education institutions to deliver online instruction to adult learners, thus permitting learner interaction with both peers and teachers (McDonald \& Postle, 1999).

The proliferation of these computer-mediated communication technologies for online teaching in adult and higher education has been said to help provide better access, convenience, and flexibility as a way to support adult learners' educational opportunities (Eastmond, 1998). According to Eastmond (1998), the use of these technologies has held "important educational promise for engendering active and experiential learning, encouraging reflection and application, and fostering collaboration and individualized construction of meaning in learning communities" (p. 40). He further indicates that online courses call for more reflection as learners

SIMONE C. O. CONCEIÇÃO, PhD, is an assistant professor of adult and continuing education and teaches courses in the areas of distance education, use of technology with adult learners, instructional design, and adult learning at University of Wisconsin-Milwaukee. Her research interests include adult learning, distance education, instructional design, learning objects, staff development for teachers, and the impact of technology on teaching and learning.

EDITORS' NOTE: This article was accepted under the previous editorship.

ADULT EDUCATION QUARTERLY, Vol. 57 No. I, November 2006 26-45

DOI: $10.1177 / 1059601106292247$

(1) 2006 American Association for Adult and Continuing Education 
consider how new information and experience relate to the context of prior knowledge and that discussions in an online environment allow learners to collaborate. With that in mind, online technologies require different ways of teaching.

Because many faculty members at institutions of higher education have been asked to teach online, it is important to consider their perspectives on teaching adults in a computer-mediated environment. One way to understand how faculty members experience online teaching is by studying online teaching situations as they unfold, using faculty members' reconstructed experiences, and elaborating on the meaning that they assign to those experiences.

\section{DEFINITION OF TERMS}

Distance education refers to instruction that occurs when there is a difference in time, location, or both. There are a variety of distance education delivery systems: correspondence, broadcast, teleconferencing, computers and digital technologies, and the Internet and World Wide Web. In this article, online instruction refers to instruction in which learners and instructor are at a distance but connected to the Internet and Web.

\section{LITERATURE REVIEW}

Studies on the use of computers to aid classroom instruction have indicated that dramatic changes have occurred in college teaching since the $1980 \mathrm{~s}$ when a growing number of faculty started using a variety of technologies to supplement traditional instruction (Baldwin, 1998; DeSieno, 1995; Green, 1996, 1997). However, today teaching in a computer-mediated environment involves more than just using the medium to supplement instruction. The advent of distanceeducation delivery systems and the widespread use of online instruction have redefined the way that higher-education faculty experience teaching.

Much of the research related to online instruction investigates instructors who have taught partially online (Annand \& Haughey, 1997; Conceição-Runlee \& Reilly, 1999; Diekelmann, Schuster, \& Nosek, 2000). Research related to faculty who participate in online teaching in higher education has focused mainly on the changing role of the instructor, teaching tasks, and faculty planning, design, and delivery of online instruction. Studies that investigate instructors' experiences in an online environment are limited.

\section{Role of the Instructor}

The distance education literature has described the role of the instructor in higher education from various perspectives using different terms and explanations. One common descriptor found in the literature is "facilitator," no matter what 
type of technology is used (Anderson, Rourke, Garrison, \& Archer, 2001; Conceição-Runlee \& Reilly, 1999; Easton, 2003).

Conceição-Runlee and Reilly (1999) conducted a study on the interaction of higher-education faculty with learners using a hybrid approach that combines online interactions with face-to-face meetings. Their phenomenological study describes the role of the faculty member as a facilitator who moves from the center of instruction to the sidelines. When compared with face-to-face discussions in which comments would typically be directed to the instructor, online conversation proved to be much more learner-centered because the online discussion moved to whoever logged on next.

In their qualitative study of role changes when faculty become virtual professors, N. W. Coppola, Hiltz, and Rotter (2002) identified three faculty roles: cognitive, affective, and managerial. The cognitive role is connected with the mental processes of learning, information storage, and thinking. The affective role is influenced by the relationships between students, faculty, and the classroom environment. The managerial role relates to class and course management. In analyzing their findings, N. W. Coppola et al. described these cumulative roles as a change in "teaching persona" (p. 9). This change in teaching persona is because of the formality of communication and lack of spontaneity when interacting with students. Formality of communication is directly related to the precision of instructions given to students. Even though the teaching process was described as formal, instructors found their relationship with students to be more intimate. In this case, class management adds a new dimension to the role of the instructor because the cognitive, affective, and managerial tasks affect the work and the instructor's relationship with students.

Anderson et al. (2001) provided a different perspective on the role of the instructor. They use a framework to provide the context of instruction. Their research is based on a model of critical thinking and practical inquiry. This model contains three components of teaching and learning in a text-based environment: cognitive presence, social presence, and teaching presence. Three major instructor roles emerged from their study: designer of the educational experience, facilitator and co-creator of a social environment, and subject matter expert. These three roles have characteristics similar to the roles found in N. W. Coppola et al.'s (2002) study. Anderson et al. (2001) stated that the teaching presence consists of three characteristics: design and administration, discourse facilitation, and direct instruction. Design and administration demand something comparable to the managerial role found in N. W. Coppola et al.'s study, as the instructors must be more explicit and transparent in their planning. Discourse facilitation requires cognitive and affective effort on the part of the instructor to maintain the interest, motivation, and engagement of students in active learning. Direct instruction involves intellectual and scholarly leadership by sharing subject-matter knowledge with students. The instructor must be able to set the climate of the class and 
model the qualities of a scholar, both of which require cognitive and affective effort.

Based on the role of the instructor and relationship of instructor with students, the literature characterizes teaching as learner-centered: The teaching activity focuses on the learner and learning. The key to learning is "what [learners] do, not what teachers do" (Beaudoin, 1990, p. 21). This process is highly personalized. The institution and the instructional personnel are responsible for facilitating and enhancing the process. In this case, the faculty member has to adjust to monitor and evaluate the work of learners instead of being the source of authority and knowledge (McDonald \& Postle, 1999). Here the instructor is not only the facilitator but also the instructional designer, subject-matter expert, and course manager. With all the changes in the role of faculty, the "teaching function is not becoming obsolete, but the role is being transformed" (Beaudoin, 1990, p. 22). The challenge is for faculty members to modify conventional teaching behaviors and to gain the skills necessary to become effective online instructors.

\section{Teaching Tasks}

The changing role of the instructor is supported by the new tasks encountered by faculty when teaching online. These tasks start during the development phase of the course and continue until the course is delivered. Tasks employed during the development phase are related to the instructional design and organization of the course. According to Anderson et al. (2001), these tasks include setting the curriculum (i.e., building curriculum materials), designing methods (i.e., repurposing lecture notes, mini-lectures, personal insights, and other customized views of course content), designing and administering an appropriate mix of group and individual activities that take place during the course, establishing time parameters (i.e., timelines for group activities and project work), and establishing "netiquette" (i.e., providing guidelines and tips, modeling appropriate etiquette and effective use of the medium). N. W. Coppola et al. (2002) called these tasks "managerial"; the instructor spends a lot of time gathering and organizing course materials.

Tasks related to the delivery of the course involve some type of interaction between students, content, and technology. According to N. W. Coppola et al. (2002), these tasks are categorized as cognitive, affective, and managerial. Cognitive tasks include responding to questions; editing questions and responses to questions; thinking, reasoning, and analyzing information; and helping students to engage in rehearsing and retrieving information. Affective tasks comprise behavior related to influencing students' relationships with the instructor and with other students in the virtual classroom environment. Managerial tasks during the delivery of the course include getting students into the conference as well as interactions with other support staff, motivating and coordinating students to participate in the course, and monitoring and evaluating student learning outcomes. 
Other tasks identified by Anderson et al. (2001) employed during the delivery of the course include facilitating discourse, which means regularly reading and commenting on student postings; establishing and maintaining the discourse that creates and sustains social presence; encouraging, acknowledging, or reinforcing student contributions; setting the climate for learning; sharing responsibility with each student; attaining agreed-on learning objectives; supporting and encouraging student responses; drawing in less active participants; and assessing the efficacy of the process.

Anderson et al. (2001) described direct instruction as one of the instructor tasks. This task consists of presenting content/questions, focusing the discussion on specific issues, summarizing the discussion, confirming understanding through assessment and explanatory feedback, diagnosing misconceptions, responding to technical concerns, and injecting knowledge from diverse sources such as textbooks, articles, the Internet, and personal experience. The direct instruction tasks include functions similar to what N. W. Coppola et al. (2002) described as cognitive or affective tasks.

\section{Faculty Planning, Design, and Delivery of Online Instruction}

Four significant themes in the literature related to the planning, design, and delivery of online instruction include time, effort, support, and compensation. Findings related to the planning and design of online teaching report that advanced preparation and organization are key aspects for the successful operation of computer-mediated instructional activities. Compared with traditional courses, this requires more development and design time for instructors (Bower, 2001; Cohen \& Ellis, 2002; Easton, 2003). Faculty experiences in planning instruction indicate that the preparation time begins long before the class starts; however, during the course of recurring online teaching experiences, faculty spend less time on preparation for distance courses taught in the same environment (McKenzie, Mims, Bennett, \& Waugh, 2000; Pachnowski \& Jurczyk, 2003).

In their study of a program in an academic environment, Sellani and Harrington (2002) found that the delivery of online teaching is more labor-intensive because faculty complained about the amount of time needed to grade papers and respond to questions. Young (2002) stated that online teaching redefines faculty schedules, duties, and relationships with students during the course delivery. Instructors may have to rearrange their daily routines and become more accessible to students.

In Conceição-Runlee and Reilly's (1999) study, faculty members expressed that the online environment gave them a sense of omnipresence. This is a result of having the online discussions always there, just a click away. Although the response time was random, the teaching experience was described as overwhelming because it required a dramatic change of pace from traditional teaching in which the instructor lectures for 50 minutes. The overwhelming nature of online teaching was intensified by the abundance of ongoing messages and comments 
posted by learners asynchronously. A common experience expressed by faculty regarding the continuous presence of the class was the amount of time it took for faculty to review all the postings. Although one faculty enjoyed "checking in frequently ... to see how things were going," another described the experience as "difficult to remember what [one] said by the time [another person] responds" (Conceição-Runlee \& Reilly, 1999, p. 57).

Three studies of online teaching experiences have tried to address the issue of faculty workload by comparing prior regular classroom teaching with online teaching (DiBiase, 2000; Hislop \& Ellis, 2004; Visser, 2000). Visser's (2000) study compared his own experience as an instructor of a new online course with prior experience teaching a regular classroom course. The results of his study indicate that the time and effort spent on online course development and delivery are greater than that of regular classroom teaching. However, he suggests that the development, delivery time, and effort may partially depend on the experience of the instructor and the level of institutional support.

DiBiase's (2000) yearlong study of his own online teaching compared to his regular classroom teaching of the same course contradicts Visser's assumption that online teaching requires more time. According to DiBiase, the total teaching and maintenance time spent per learner in his online course was less than that involved in his regular classroom teaching. He believes that the effectiveness and efficiency of an online course is directly related to "the amount, and the quality, of the instructional design and development effort that produced it" (DiBiase, 2000 , p. 19). He states that diverse audiences may require more or less time per learner in the development and maintenance of courses; thus, regular classroom and online courses should evaluate the contexts of their intended learners.

Hislop and Ellis (2004) investigated whether teaching online takes more effort than teaching in a traditional class setting by having faculty keep track of their time for seven comparable pairs of online and traditional course sections. Their findings indicate that the amount of time spent teaching online is not greater than the amount of time teaching in a traditional setting, as other studies have suggested. They indicate that the time spent teaching online is more fragmented as opposed to the chunk of time for teaching a traditional course. They also suggest that teaching online may not take more time, but it may take more effort, as a larger number of fragmented activities may intensify the effort to teach by augmenting cognitive overhead.

Visser (2000) suggested that the development, delivery time, and effort may partially depend on the level of institutional support. A 1997 survey by the National Center for Education Statistics shows that $60 \%$ of higher-education institutions offer some kind of training for faculty who teach at a distance, but only $13 \%$ of that number make training in curriculum development a requirement and $17 \%$ require training in teaching methods (Bower, 2001).

Support can be offered in a variety of ways, such as pedagogical and technical training and monetary compensation. Studies about pedagogical and technical 
preparation show that training offered by institutions was deemed by instructors to be relevant and helpful for teaching online (Bower, 2001; Kosak et al., 2004). Studies about institutional support indicate that some institutions initially provided accommodations to faculty such as workload adjustments, release time, monetary support, or credit toward promotion and tenure; however, this type of support decreased as time passed (Bower, 2001; McKenzie et al., 2000; Pachnowski \& Jurczyk, 2003). Support and compensation have proven to be important aspects of online teaching experiences.

Although the available research demonstrates that online teaching has major implications for practice related to the role of faculty teaching online, the tasks that faculty employ, and the planning, design, and delivery of online instruction, the literature is mostly based on personal experiences, expert opinion, and conventional wisdom. More recently, an abundance of survey-based research shows faculty perspectives, needs, and challenges in the distance-teaching environment. As online instruction has become more prolific, studies about the role of the instructor and the new tasks employed in this environment have emerged. However, a few studies on the experiences of faculty teaching online offer significant insights. Therefore, this article presents a phenomenological study as a way to seek in-depth information pertaining to the experiences of faculty who teach exclusively online without ever having to meet their learners.

\section{RESEARCH PURPOSE AND QUESTION}

The purpose of this study was to understand the experiences of college faculty who teach online. The motivation for doing this study was the result of the author's own experience as an online instructor, work as an instructional designer, and concern about issues of faculty development. Since 1996, the author has actively worked with college faculty to find ways to use computer-based technologies in support of teaching and learning. Currently, the author coordinates an online master's program in adult education and continues to consult faculty on the instructional design of online courses. Through this spectrum of experience and involvement with the use of computer-based technologies and online teaching, especially working with college faculty, the author has come to believe that the sharing of experience about online teaching can help increase personal and institutional capacity by increasing awareness about pedagogical issues in the online environment, improving the quality of online instruction, influencing policy makers to better support faculty training and performance, and encouraging faculty who are new to the online environment. As a researcher, it is important to know more about the online teaching phenomenon. The author believes that experience is a valid source of knowledge and that faculty's everyday online teaching experiences contain rich insights into various phenomena (Becker, 1992).

This study addressed the following question: How do college faculty perceive and describe their online teaching experiences in a computer-mediated environment 
that is fully absent of physical presence? This research question points to a phenomenological study of the online teaching experiences of college faculty. A study of such kind can "facilitate the expansion and development of more adequate theory building" (D. Coppola, 1983, p. 1). A phenomenological study is pre-theoretical in nature. It provides insight and "crucial information in theoretical, empirical, and intervention realms" (Becker, 1992, p. 48). This type of research allows readers to begin to understand and empathize with the phenomenon of online teaching and, in turn, determines the extent to which interpretations make meaning for them (Bloomer \& Hodkinson, 1997).

\section{RESEARCH DESIGN}

A phenomenological study design was considered the most suitable for this study because it provided a clear process for setting aside the researcher's preconceptions about the phenomenon of online teaching and resulted in a shared examination of the phenomenon by the researcher and study participants. The goal of the phenomenological study was to explore the phenomenon of online teaching as experienced by college faculty. Phenomenology was first developed as a philosophy by Husserl and then expanded by Heidegger, Sartre, and Merleau-Ponty (Kvale, 1996). Husserl introduced the phenomenological concept of the "lifeworld" to describe the world as it is experienced, and Merleau-Ponty developed phenomenology as a methodological tool through which the complex lifeworld is revealed and understood (Dahlberg \& Drew, 1997). Phenomenological research approaches are either hermeneutical or empirical. The hermeneutical approach focuses on consciousness and experience (Moustakas, 1994) and uses literary texts and works of art to understand human life (Becker, 1992). Conversely, the empirical approach describes how one orients oneself to lived experience. This study followed the empirical phenomenological research inquiry based on Moustakas's (1994) approach, which focuses on a situation in which the investigated experience occurred. The researcher looks for descriptions to construct structures of the experience.

Two sampling strategies for selecting participants were employed: snowball sampling and criterion-based sampling. Snowball sampling involved identifying ideal participants by asking knowledgeable people for referrals (Merriam, 1998; Patton, 1990). Criterion-based sampling involved selecting participants that met a predetermined criterion of importance (Patton, 1990). In this study, participants met the following essential criteria: (a) Participants had to have an interest in computer conferencing and must have taught online, (b) the teaching experiences of faculty did not include formal face-to-face interactions with students during the course (the entire course activities had to be online), (c) participants had to actively practice instruction in a computer-mediated environment at the highereducation level and be in a tenured or tenure-track position, (d) participants must have previously taught the same online course(s) in a computer-mediated 
environment, and (e) participants had to be willing to engage in an interview process, which also involved follow-up interviews.

Data were collected using semistructured, open-ended interviews conducted at the participants' site of preference, with follow-up interviews via electronic mail. The investigator followed the essential processes that characterize a phenomenological analysis: epoche, phenomenological reduction, imaginative variation, and synthesis of meanings and essences.

The epoche was the process in which the investigator set aside everyday understandings, prejudgments, and biases about online teaching. During the phenomenological reduction, the investigator's task was to look at the phenomenon of online teaching and to describe it in textual language-the focus was on the online teaching experience and its meanings. During this stage, the investigator uncovered, defined, and analyzed the elements and essential structures of the phenomenon of online teaching. Data were then grouped into clusters, and repetitive, irrelevant, or overlapping data were removed, leaving only the textual meanings and invariant constituents of the phenomenon of online teaching. Next, the imaginative variation was performed on each theme; this entailed describing the structural elements of the phenomenon and the variation of possible meanings and perspectives of the phenomenon from different vantagepoints. The next step involved an intuitive-reflective integration of the composite textual and composite structural descriptions to develop a synthesis of meanings and essences of the experience (Becker, 1992; Giorgi, 1997; Merriam, 1998; Moustakas, 1994; Patton, 1990). Member checks, peer examination, and detailed accounts of participants' experiences were used to increase the trustworthiness of this inquiry (Denzin, 1989; Merriam, 1998; Mertens, 1998).

\section{CONTEXT OF THE STUDY}

In this study, participants used a variety of communication technologies to deliver instruction, including customized network environments that were developed in-house, a stand-alone conferencing program (e.g., FirstClass, WebBoard, Discus) or an integrated software program (e.g., Blackboard Courselnfo, LearningSpace, WebCT) that incorporated course-management tools, application sharing, conferencing components, a calendar, assessment and monitoring components, and administrative aspects that allowed instructors to have control of the course design and delivery.

A total of 10 college faculty members ( 5 women, 5 men) teaching at 4-year institutions of higher education from different geographic areas of the United States and Canada were included in this phenomenological study. Selected participants were from different academic disciplines, including accounting management, adult education, business management, human resources, library science, management information systems, nursing, and workplace learning. The faculty status of participants included: full professor $(n=3)$, associate professor $(n=2)$, 
and assistant professor $(n=5)$. The online teaching experience of participants ranged from 2 years to 16 years. Participants represented four different nationalities. It is important to note that these faculty members were not teaching single courses (with the exception of 1 ) but courses that were part of an ongoing education program offered online to undergraduate and graduate students. The majority of the courses were at the graduate level. To maintain the confidentiality of study participants, pseudonyms are used to refer to the 10 faculty members who participated in the study. Table 1 displays the profile of study participants.

\section{FINDINGS}

The two major themes that emerged from the phenomenological data analysis of the meaning of faculty members' online teaching experience are (a) work intensity and (b) rewards.

\section{Work Intensity}

A common remark among study participants concerned the intense work involved in designing and delivering an online course because of the length of engagement before and during instruction and the depth of engagement during course delivery. Like any process that involves the full use of one's ability, energy, or resources, online teaching was said to be challenging.

Length of engagement. According to study participants, teaching an online course required more time to design and deliver instruction than a face-to-face course. Study participants explained that designing an online course required more time from the instructor because it involved (a) organizing content, (b) presenting information that addressed different learning styles, and (c) providing lecture notes in advance.

Tony explained the difference between the two modes of instruction as they relate to the organization of content, saying,

Things are much more structured and perhaps rigid than they are in a regular course. When I teach a course, oftentimes I find topics and readings and things of interest the day before I teach. I read a book, I read a new journal article, I would see something in the paper. I bring that into class. And I modify and adjust my syllabus accordingly. In an online environment, I have to make decisions about what to teach, what to talk about, what content to cover 6 months in advance, without knowing the audience, without knowing their specific needs, without being able to react to what's coming from the class.

When presenting information, Olivia was concerned about individual learning styles, which involved intense work in course preparation. She explained, "There seems to be some discrepancy between how people prefer to know about [course materials]. Some people want them all up front." Others favor accessing 


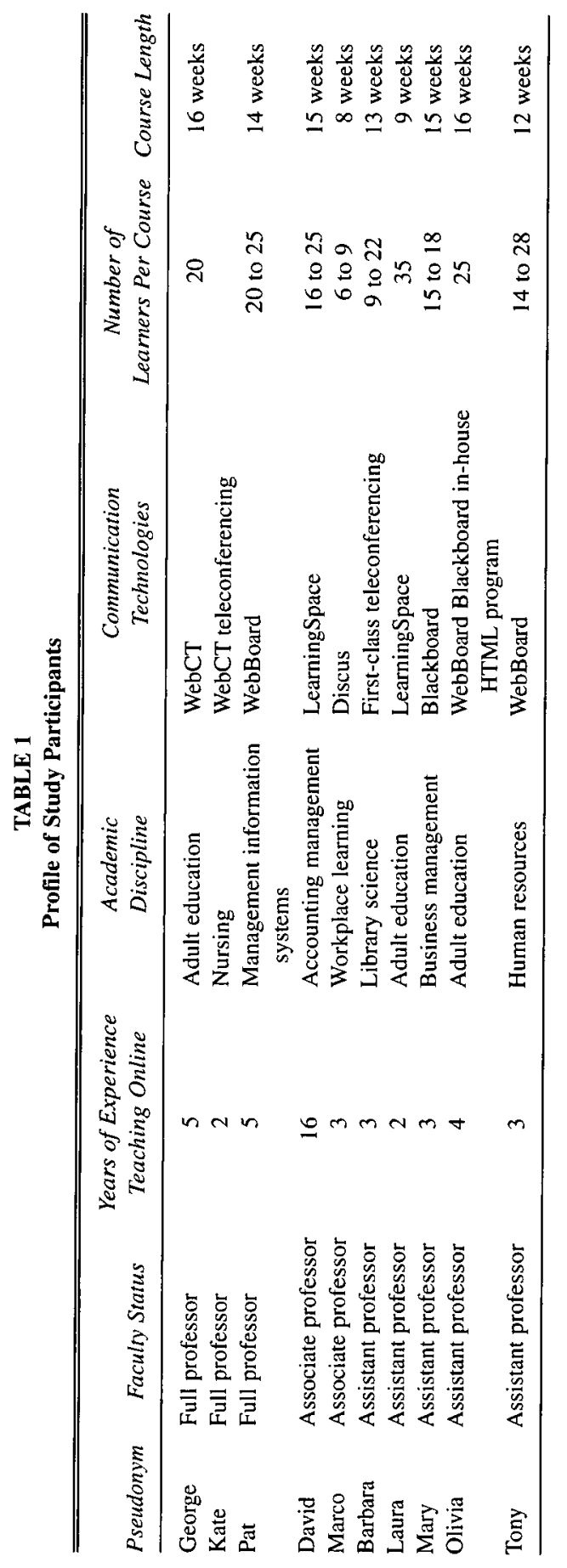


materials just before they are due. She further noted that learners reacted differently to the way that course materials were arranged in the software program.

David acknowledged the intensity of work when preparing the course because he provided lecture notes in advance. Barbara said that there was a need to foresee and to have everything ready by the start of the class because it could be overwhelming for the instructor to conduct and create the course simultaneously. She explained,

Because if you're trying to write lectures or prepare PowerPoints or activities, and keep up with the dialogue, you can't do it. I learned that early enough; you can't do both. You have to really prepare your materials whether or not they are in exact final format.

Delivering an online course involved teaching functions such as (a) class management, (b) monitoring and assessment of learner performance, (c) course clarification, and (d) course continuity.

Class management functions included administering and maintaining the course in the integrated software program. These functions included putting up the course documents, updating the external links, and managing the threaded discussions. Olivia stated that unless she was careful enough, these functions could be more administrative than teaching.

As part of class management, Mary recognized that she had to do more preplanning when proceeding with the threaded discussions:

When I facilitate a discussion online, I can't just say, "OK, everybody, what do you think about this?"' I can't just pose a question. I have to pose a question and then they have to provide strands of that question ... I don't want to leave the impression that I restrict the discussion to just what I can think of. But I have to try to envision ahead of time the way this can go, particularly because of the sizes of my classes.

Mary recognized that monitoring learner performance was time consuming by contrasting her online experience with her face-to-face teaching: "You don't have the 2.5-hour class that meets that week, but instead you're sitting back reading everything every [learner] does and reflecting on it and providing feedback." Furthermore, Mary stated that assessing learner performance required more time because of record keeping:

In a traditional class, we want participation as well, but you don't sit there in a classroom and record: [Learner] A made three comments tonight and [Learner] B was silent the whole night. You don't do that. You have other ways of trying to gauge how they're developing knowledge and applying it. But in this kind of a course, participation is critical. Everybody's getting something out of it ... because these discussions, again, are to facilitate the dialogue.

Study participants acknowledged that providing course clarification during online-course delivery was another intense task. Clarification of course expectations 
or course activities was completed through instructor feedback to all learners by logging in multiple times a day and providing constant feedback in a specific location in the course site. For example, Kate used a private area in the integrated software program for clarifying expectations about the course, asking questions, and announcing course activities. Olivia clarified assignments by posting announcements on the front page of the course site and sent learners e-mail messages.

Another aspect of online-course delivery was maintaining course continuity, which was described by David as the ability to give people "the look and feel" of talking and interacting with "real people." For David, this meant that he had to be online every morning, responding in the forum, answering e-mail, entering grades, and so on.

Pat recognized that teaching an online course involved a much higher workload in comparison to regular classroom teaching because of the individual interactions with learners, even though these interactions helped maintain course continuity. He explained, "For every course that I teach online, the amount of work-not just to develop it, but delivery of it-it's at least $50 \%$ more than the campus course." The main reason for the difference between online and face-to-face courses was the number of interactions that he had with individual learners. For on-campus classes, he indicated, "I go to class and deliver my lecture and I don't hear or see from the [learners] till next week." Pat received e-mail from his online learners almost every day, sometimes several interactions a day when the semester began. Occasionally, several of his learners communicated with him up to 3 times a day. Because the course was available 24 hours a day, communication was nonstop.

Barbara concurred with Pat regarding the nonstop nature of online teaching, saying, "You're just online nonstop. You just can't leave." She developed strategies to manage the nonstop nature of online teaching by "having a no-post day" once a week. The group of learners decided on what the no-post day was and called it a "reading day," a day when people could use the time to get caught up with the messages or do course reading.

Reading course postings was a continuous task for the instructor in the online environment. This meant more than just reading a few comments here and there. Kate explained, "[Learners] were reading their own team comments. But I read everybody's comments." This involved a more extended engagement and workload.

Because online technology has the potential to give access to instruction 7 days a week, 24 hours a day, it can also create expectations for the instructor. Marco was concerned that some of his learners expected him to be accessible 7 days a week, 24 hours a day, in part because they did their work on weekends. Marco further commented,

I want to be able, if I want, to choose to go online on the weekends. But I don't want a situation where it's expected of me to be going online on a Sunday evening. I want time with my family. 
Depth of engagement. For the majority of the study participants, the online interactions were work intensive because they involved a strong cognitive and affective effort during the delivery of instruction. Cognitive effort is associated with the mental processes that faculty used to deliver instruction, whereas affective effort pertains to feelings resulting from an emotional state of consciousness partly because of the lack of physical presence.

Faculty acknowledged that teaching online required intense cognitive effort to (a) stay engaged in a conversation, (b) keep the class focused, (c) distinguish between administrative and personal information, (d) pursue a comprehensive discussion, and (e) create a mental image of what learners looked like.

According to Olivia, one of the challenges of online teaching was to stay engaged in a conversation and read the emotional tone behind it. She acknowledged that to interact online, the instructor took more time to respond to learners for two reasons: (a) Instructors had to pay attention to two conversations ("You have to close [a message] up, open up another one") and (b) the instructor could not see or hear emotions, tones, body language, and eye contact.

Barbara indicated that one of the biggest challenges for her, as an instructor, was to keep the online class focused, present information in a truly engaging manner, and ask questions in the right way. For Tony, pursuing comprehensive discussion was challenging because the group seemed to jump from topic to topic, and the discussions did not go deep enough: "It's very canned instruction and ... spontaneity is lost in that .... We seem to jump from topic to topic a lot. It's hard to really pursue an in-depth discussion on topic with give and take. It's hard to do that in writing."

Marco indicated that it was difficult to distinguish between information that was purely administrative and information from learners that needed personal attention. He described his experience by contrasting face-to-face instruction with online interaction:

When you're teaching face-to-face, there's a clear bridge between sitting in your office and then going to a classroom and experiencing that teaching environment. Whereas you're in the office, and you're reading a screen, and there isn't that physical person as well as the psychological person. ... I mean, you have to give a much more comprehensive, more thoughtful response. It makes you do research because your response to a question is there for everyone to read, whereas face-to-face you can say something and you say something off the cuff or you're not sure. But when you're having to post it, you have to be sure.

Olivia expressed that she felt a need for a more personal interaction with her online learners, a need to see them to feel more personal:

I miss the interaction. I miss seeing the [learners]. I'm a very visually oriented person, and when I get an e-mail from one of the [learners], a picture pops up immediately. I've got names and faces put together, and that's important for me. 
Faculty acknowledged that teaching online also required intense affective effort: There was a need to be more attentive to emotionally engage with learners, and it was difficult to be personal online. In an online environment, impersonal experiences were described as the ones that lacked immediate feedback and involved formal communication.

Marco compared online learning with performing on the stage and filming for television to illustrate the lack of immediate feedback: "The difference being that they don't have the feedback and they can't hear the laughter or the response of the audience. Online teaching vis-à-vis face-to-face teaching is similar to performing on stage or filming in front of a camera."

Marco also pointed out that, similar to a face-to-face class, in an online environment, "you don't use dialect slang. You talk more formally compared to someone you know well. Then you start being more informal in the choice of vocabulary."

\section{Rewards}

The second major theme that emerged from the phenomenological analysis of the meaning of the online teaching experience is rewards. Although the online teaching experience of college faculty was work intensive, most of the study participants acknowledged that the teaching experience gave them some type of satisfaction. There was a wide array of perspectives related to the type of satisfaction gained from the experience of designing and delivering an online course. Words such as "stimulating," "invigorating," "exciting," "rewarding," "satisfying," "gratifying," and "empowering" convey the sense of satisfaction the experience gave to them.

Olivia recognized the online teaching experience as stimulating. She explained the rewarding nature of the online environment, saying, "When there's an 'aha' moment or 'light bulb' moment that happens, even in spite of this environment, that's very rewarding. It's a real asinine example, but we still don't know what caused it to be." Pat stated that online teaching can be invigorating if the instructor wants it to be: "There might be online courses and programs here and there that may not be as vigorous ... as face-to-face, but online instruction in general can be at least as good or even more invigorating if you really want."

Laura thought that although online teaching was "very time consuming ... [it was also] rewarding" because "it's just fun logging in and seeing what people have to say. And it's exciting watching the [learners] really respond and get into it ... and that's what kind of keeps me going ... it's kind of exciting to rethink of a new way to deliver instruction." However, she did not know whether it was more rewarding than face-to-face instruction but said that online teaching "is probably rewarding in a different way." 
Barbara enjoyed watching learners interface with each other online. She stated, "You see [learners] going back and forth, even in a non-real-time environment, when you are watching messages back and forth in what seems to be real timethat's really exciting."

Like Barbara, George was also excited when he watched learners interface with each other in the online environment. Mary indicated that the online teaching experience was gratifying because she got to know her learners better:

There's a tremendous gratification in [online teaching] because of how well l get to know the [learners], and I believe the opportunities I have to assess their application of the knowledge and skills that we're talking about during the semester.... You're sitting back reading everything every [learner] does and reflecting on it and providing feedback. ... The way I do it is more time consuming, but it's also much more gratifying. I feel like I can have a greater impact on each individual [learner].

Pat thought the experience was "rewarding in a sense that you can have different types of [learners] in your class" and learn from them. He explained that online learners can be literally from anywhere. The class's broad pool of learners brings diversity to the group.

Pat's interest in gaining knowledge from his online teaching experience is paramount. He stated that while teaching online for about 6 years, "I have learned ... from my online [learners] a lot more than I have learned the previous 15 years from my on-campus [learners]."

Like Pat, Tony felt that he learned a lot more from his online learners than face-to-face learners because the profile of the online learners had a tremendous influence on how the experience evolved. Tony explained, "We're reaching different segments of [learners], mid-career professionals who have a lot to contribute ... and we would not reach these [learners] otherwise. And as a teacher, that's rewarding."

Barbara also saw online teaching as a learning experience because it was fun and exciting to interact with learners who have related work experience: "It's work intensive. It's hard. But in the long run, it's very rewarding. And it's a learning experience for the instructor . . . because the people that I teach are working professionals in the field, the practitioners versus the researchers." David acknowledged that online teaching was empowering because online instruction could be done from any place.

In this study, the descriptions of the online teaching experiences of faculty portray the role of the instructor as an instructional designer that designs the online course, a facilitator that engages learners in the learning process, a catalyst that instigates conversations, and a learner that participates in the learning experience. The context of this process is characterized as a learner-centered environment in which the course design and delivery is focused on activities that will meet the needs of a diverse audience. For the instructor, the process of teaching initially 
appears to be work intensive because of the length of engagement in developing and preparing course materials. As the online course design and delivery progresses, the instructor seems to be deeply involved in the process, resulting in high satisfaction. In spite of the work intensity, faculty members continue to teach online because they know that it becomes easier over time and the rewards that come with the experience are appealing.

\section{DISCUSSION AND IMPLICATIONS}

This study shows that new issues related to teaching practices have emerged because of the use of online technologies. Two of the themes found in the literature related to the experience of faculty who teach online are similar to the findings in this study: (a) the changing role of the instructor and (b) the work intensity because of the length of engagement during the course design and delivery. However, this study's findings raised new issues that have major implications for adult education. What the literature did not offer and what this study suggests is that the online experience brings new dimensions to the teaching practice when there is an absence of physical presence: (a) The length and depth of engagement during the delivery of the course differs from face-to-face teaching, and (b) the experience is rewarding in new ways.

The length and depth of engagement during the delivery of the course involved a strong cognitive and affective effort. New tasks for the instructor emerged when teaching online because of the types of interactions that took place when there was an absence of physical presence. These interactions were shaped and guided by the content, and it was the instructor's task to manage learning in the online environment. Course delivery involved teaching functions such as class management, summarizing content, monitoring and assessment of learner performance, course clarification, and course continuity.

The design of the online course was learner centered. The course design focused on developing learners' thinking skills and involved regular interactions with the learners. Interactions and learning activities were structured in a way that challenged learners' comprehension of content, encouraged new ways of thinking about course concepts, and fostered different approaches to thinking. It meant that for the online instructor, the process of teaching involved a profound cognitive effort to keep the class focused (by presenting the information in an engaged way), assist students in pursuing a comprehensive discussion, stay engaged in a conversation with the learners (by reading the emotional tone behind the message), and create a mental image of what learners looked like.

Because of the lack of body language, eye contact, and tone of voice, online instructors used affective strategies when interacting with learners to be personal online and to emotionally engage with learners. Some of these strategies included providing immediate feedback, distinguishing between administrative and personal 
interactions, or connecting with learners on a regular basis. These approaches to teaching required an emotional effort to create a climate of trust and respect, engage empathically with individual learners, guide learners through content, and provide encouragement and support to learners. The online instructor was more of a facilitator rather than someone who provided answers to questions, even though content was designed ahead of time with no input from learners because of institutional constraints.

Although all study participants described online teaching as intense work, they also indicated some level of satisfaction with the experience. The common expression was: "Teaching online is a lot of work, but it is also rewarding." Faculty reported that online teaching was satisfying when they were personally engaged in the process of designing and delivering instruction. This process was rewarding because the instructor was learning by doing; it was invigorating when the experience was dynamic, exciting because it required rethinking and reflecting on how to deliver instruction in a new way, enjoyable when watching learners interface with each other, gratifying because they got to know their learners better, and satisfying when they gained knowledge from interacting with learners.

This study has practical implications for adult education as it relates to teaching improvement and instructional design. Studying the meaning of the online teaching experience can be beneficial to those who have not explored the online teaching environment but who may be encouraged through the experience of others. This study allows readers to begin to understand the phenomenon of online teaching and, in turn, determine the extent to which interpretations make meaning for them.

This study can help faculty members gain an instructional perspective on online teaching and also recognize that although it may require a longer lag time for the planning and preparation of online instruction initially, it can also be a rewarding experience. In addition, this study can help faculty rethink the role of the instructor in light of the type of teaching practices that one experiences while teaching online.

Looking at the findings of this study, participants did not refer to the assistance of instructional designers in the development of their online courses even though most of the participants described their experiences as positive. There is a potential to involve instructional design personnel during the design phase of the course development, which could result in less work for faculty. This study can also assist instructional designers by raising their awareness of the experiences faculty encounter when teaching in an online environment. This knowledge can enable instructional designers to advise faculty of less time-consuming ways to design and deliver instruction. Further research on the connections between faculty experience teaching online and institutional support can be relevant to answer some of the questions related to the amount of time to design and deliver instruction. 


\section{CONCLUSIONS}

Throughout this study, a key concern has been the changing role of college faculty in higher education because of the rapid expansion of online teaching. This role has changed to one of support in the teaching-learning process. Teaching and learning become a partnership resulting from learner-centered environments. These environments are not controllable and predictable; they require faculty members to think about themselves very differently as instructors, recognize the changes in the educational paradigm, engage in new kinds of activities, and reconsider the meaning of being an expert.

In this new educational paradigm, teaching is no longer a one-way mode of instruction with the faculty member as the only expert. Knowledge becomes an activity shared by the online learning community. Expertise is part of a collective effort between learners and the instructor. Teaching becomes a constructive process because each phase involves a challenging situation that needs to be resolved.

\section{REFERENCES}

Anderson, T., Rourke, L., Garrison, D. R., \& Archer, W. (2001). Assessing teaching presence in a computer conferencing context. Journal of Asynchronous Learning Networks, 5(2), 1-17. Retrieved June 19, 2006, from http://www.aln.org/alnweb/journal/jaln-vol5issue2v2.htm

Annand, D., \& Haughey, M. (1997). Instructors' orientations toward computer-mediated learning environments. Journal of Distance Education, 12(1-2), 127-152.

Baldwin, R. G. (1998). Technology's impact on faculty life and work. In K. H. Gillespie (Ed.), New directions for teaching and learning: Vol. 76. The impact of technology on faculty development, life, and work (pp. 7-21). San Francisco: Jossey-Bass.

Beaudoin, M. F. (1990). The instructor's changing role in distance education. The American Journal of Distance Education, 4(2), 21-29.

Becker, C. S. (1992). Living and relating: An introduction to phenomenology. London: Sage.

Bloomer, M., \& Hodkinson, P. (1997). Moving to FE: The voice of the learner. (ERIC Document Reproduction Service No. ED 414 494)

Bower, B. (2001). Distance education: Facing the faculty challenge. Online Journal of Distance Learning Administration, 4(2). Retrieved June 19, 2006, from http://www.westga.edu/ distance/ ojdla/summer42/bower42.html

Cohen, M. S., \& Ellis, T. J. (2002, November 6-9). Developing criteria set for an online learning environment. Proceedings of 32nd American Society for Engineering Education/Institute of Electrical and Electronics Engineers 2002; Frontiers in Education Conference, Boston.

Conceição-Runlee, S., \& Reilly, K. (1999, October). Experiences of faculty members who interact with students in an online environment. Paper presented at the Midwest Research to Practice Conference, University of Missouri-St. Louis.

Coppola, D. (1983). Phenomenological research with children: Guidelines to follow and implications for the practitioner. (ERIC Document Reproduction Service No. ED 237 228)

Coppola, N. W., Hiltz, S. R., \& Rotter, N. (2002, Spring). Becoming a virtual professor: Pedagogical roles and asynchronous learning networks. Journal of Management Information Systems, I8(4), 169-189. 
Dahlberg, K., \& Drew, N. (1997). A lifeworld paradigm for nursing research. Journal of Holistic Nursing, 15(3), 303-317.

Denzin, N. K. (1989). Interpretive interactionism. Newbury Park, CA: Sage.

DeSieno, R. (1995). Netlaw: The faculty and digital technology. Educom Review, 30(4), 46-48.

DiBiase, D. (2000). Is distance teaching more work or less work? The American Journal of Distance Education, 14(3), 6-20.

Diekelmann, N., Schuster, R., \& Nosek, C. (2000, June). Creating new pedagogies at the millennium: The common experiences of University of Wisconsin-Madison teachers using distance education technologies. Distance Education Systemwide Interactive Electronic Newsletter, 5.7. Retrieved from http://www.uwsa.edu/olit/tt/98.pdf

Eastmond, D. V. (1998). Adult learners and Internet-based distance education. In B. Cahoon (Ed.), New directions for adult and continuing education: Vol. 78. Adult learning and the Internet (pp. 33-41). San Francisco: Jossey-Bass.

Easton, S. S. (2003). Clarifying the instructor's role in online distance learning. Communication Education, 52(2).

Giorgi, A. (1997). The theory, practice, and evaluation of the phenomenological method as a qualitative research procedure. Journal of Phenomenological Psychology, 28(2), 235-260.

Green, K. C. (1996). The coming ubiquity of information technology. Change, 18(2), 24-28.

Green, K. C. (1997). The 1997 National Survey of Information Technology in Higher Education. Retrieved June 19, 2006, from http://www.campuscomputing.net/summaries/1997/index.html

Hislop, G. H., \& Ellis, H. J. C. (2004). A study of faculty effort in online teaching. Internet and Higher Education, 7(1), 15-31.

Kosak, L., Manning, D., Dobson, E. Rogerson, L., Cotnam, S., Colaric, S., et al. (2004). Prepared to teach online? Perspectives of faculty in the University of North Carolina System. Online Journal of Distance Learning Administration, 7(3). Retrieved June 19, 2006, from http://www.westga .edu/ distance/ojdla/fall73/kosak $73 . \mathrm{html}$

Kvale, S. (1996). InterViews: An introduction to qualitative research interviewing. Thousand Oaks, CA: Sage.

McDonald, J., \& Postle, G. (1999, March 3). Teaching online: Challenge to a reinterpretation of traditional instructional models. Paper presented at the Fifth Australian World Wide Web Conference, Southern Cross University, Australia. Retrieved June 19, 2006, from http://www.usq .edu.au/users/mcdonalj/papers/paper.htm

McKenzie, B., Mims, N., Bennett, E., \& Waugh, M. (2000). Needs, concerns and practices of online instructors. Online Journal of Distance Learning Administration, 3(3). Retrieved June 19, 2006, from http://www.westga.edu/ distance/ojdla/fall33/mckenzie33.html

Merriam, S. B. (1998). Qualitative research and case study applications in education. San Francisco: Jossey-Bass.

Mertens, D. M. (1998). Research methods in education and psychology: Integrating diversity with quantitative and qualitative approaches. Thousand Oaks, CA: Sage.

Moustakas, C. (1994). Phenomenological research methods. London: Sage.

Pachnowski, L., \& Jurczyk, J. (2003). Perceptions of faculty on the effect of distance learning technology on faculty preparation time. Online Journal of Distance Learning Administration, 6(3). Retrieved June 19, 2006, from http://www.westga.edu/ distance/ojdla/fall63/pachnowski64.html

Patton, M. Q. (1990). Qualitative evaluation and research methods. London: Sage.

Sellani, R., \& Harrington, W. (2002). Addressing administrator/faculty conflict in an academic online environment. The Internet and Higher Education, 5, 131-145.

Visser, J. A. (2000). Faculty work in developing and teaching Web-based distance courses: A case study of time and effort. The American Journal of Distance Education, 14(3), 21-32.

Young, J. R. (2002, May 31). The 24-hour professor: Online teaching redefines faculty members' schedules, duties, and relationships with students. Chronicle of Higher Education, pp. A31-A33. 
Copyright of Adult Education Quarterly is the property of American Association for Adult \& Continuing Education and its content may not be copied or emailed to multiple sites or posted to a listserv without the copyright holder's express written permission. However, users may print, download, or email articles for individual use. 